\title{
Exploring Flow Theory in TOEFL Texts: Expository and Argumentative Genre
}

\author{
Zeinab Azizi \\ International Corpus of Ferdowsi University of Mashhad, Iran \\ Behzad Ghonsooly \\ Ferdowsi University of Mashhad, Iran
}

\begin{abstract}
The present study attempts to examine optimal experience of test takers in Expository and Argumentative Genres of TOEFL texts. Flow theory was originally used by Csikszentmihalyi in 1970 to represent "optimal experience" that is characterized by intense focus, control, interest and skill challenge balance which leads to enhanced performance on a task, and provides the basis for peak performance. Different researchers have examined Flow in different fields of studies as sports, music and surgery but there has been less attention toward International proficiency tests like TOEFL. This study tries to examine the role of genre which creates more flow in text readers of TOEFL. So, two different texts from a TOEFL actual test with different genres were chosen. Then, 33 participants who were MA English students were asked to read the texts and fill out the Flow perception Questionnaire (Egbert, 2003) in the Likert format to report their perceptions of flow. By calculating mean of both texts, it was indicated that the Expository genre creates more flow in readers. In addition, to get more information, two participants were interviewed to shed more lights into findings.
\end{abstract}

Index Terms - concept of flow, sense of control, flow and motivation, expository and argumentative genres

\section{INTRODUCTION}

Because people do not like to do time-consuming, difficult and dangerous activities, they often tend to do easy activities for which they receive noticeable extrinsic rewards. This is finally called the "flow experience". The most crucial point in flow is paying much attention to do the certain job in a way that there is not any attentiveness toward the other objects beyond it. In fact there is a kind of a failure in self-consciousness throughout flow. In order to create a kind of interaction between actor and action a sort of attentional resources are needed. Indeed, during the flow "me" disappears through flow, and the "I" takes over. According to Mirlohi, Egbert, Ghonsooly (2011) Flow Theory was built up by Csikszentmihalyi (1996), who proposes that learners can experience best learning during tasks characterized by a skills-challenge balance and by a person's concern, control, and intense focus.

During our life all of us experience that reading some of texts are more interesting and challenging in comparison with the others which are boring, tedious and monotonous. For the first one we have control over the texts and we may wish to read it again and again but for the second one we may leave the text before it is finished because it is not interesting for us to continue. So, this may be type of texts that can create reading motivation and flow in readers. This effect might be created in reading passages like TOEFL. So, in this study two important genres-Expository and argumentative - are compared in TOEFL texts.

Flow

According to Csikszentmihalyi, Abuhamdeh, Nakamura (2005), in fact persons talk about flow whenever they are completely engaged in doing a task as if they forget about everything around them that is a kind of subjective characteristic of the flow. A sort of feeling that we experience during playing our favorite game or reading a book that we are interested in. Influential and deep connection in a certain task so that a person can feel every second of it can be regarded as flow as well (Csikszentmihalyi, Abuhamdeh, Nakamura, 2005).

There are three other features whenever a person experiences flow in doing a task: integration of task and awareness, feeling of management, and no feeling of passing the time. Absorption and attentiveness are entirely provided in doing a task other than forgetting the time. Consequently, people intensely absorb in an action normally talk about rapid passages of time (Csikszentmihalyi, Abuhamdeh, Nakamura, 2005).

Skills-challenge balance, attention, interest and control are different dimensions of flow. Moreover, some other features like intrinsic motivation, enjoyment, and enhancing growth have been found to be associated in creating flow. To sum up, obvious objectives, best confronts, and apparent, instant reactions are necessary aspects of actions that encourage the basically satisfying practical contribution that distinguishes flow. Certainly, these elements are not the only factors that affects on being involved in an activity. There are various studies that show the significance a person puts in doing well in an action foretells the individual's involvement in that activity. 
However, it has been shown that there are variations across people and tasks and some people are likely to experience flow more often than others even while doing unpleasant chores (Hektner \& Csikszentmihalyi, 1996).

\section{A Sense of Control}

According to Csikszentmihalyi, Abuhamdeh, Nakamura (2005), typically experiencing a sense of control—or, more precisely, not having anxiety about the loss of control that normally we experience during lots of job in our everyday life are all the characteristics of flow. This is a kind of feeling that we all experience in doing our favorite tasks (Conti, 2001). The possibility for learners to exercise control while learning, especially in difficult circumstances, has been regarded as essential in experiencing flow (Jackson \& Marash, 1996). It can be said that flow is a reason to change our distressing about doing a task into something pleasant and satisfying. This kind of distress can be happened during our job or even having relationship with others. By experiencing flow in our daily life we enjoy every moments without any stress or tiredness or fatigue. It can be a good decision to create certain situations in every stage of our life even our study or religious ritual.

Previous research provides three important situations that are central and crucial. First, when a person connects to an activity that includes obvious purposes and objectives flow takes place. Having purposes direct and leads our routines. Paying much attention to the task and emerging in the situation structure a satisfying and gratifying realm. Second, when a person provides a balance among between perceived challenges and perceived skills flow happens. (Csikszentmihalyi, M., Abuhamdeh, S., Nakamura, J., 2005). At the time of corresponding between these two factors a person completely and fully absorbed in the action. However, this stability is fundamentally easily broken. If confronts start to surpass talents, a person generally becomes worried and uneasy; but if talents commence to surpass confronts, a person calms down and becomes exhausted. At last, existence of obvious and instant reaction is one of the main prerequisites of flow. To involve in an action, one requires to frequently changing environmental needs (Reser \& Scherl, 1988). Immediate reaction informs a person how improving in the action will be happened well, and states that is it necessary to correct and change the way or to carry on the certain action. In such a way there remains a very little uncertainty about what to do subsequently. Flow happens during a task that is certainly contains negative act feedback in such a way that flow creates in a high level of challenging. But there isn't any dangerous or damaging to the activity associations. Certainly, that's easy to suppose circumstances that we deliberately educe negative reaction with the purpose of direct attention and behavior (e.g., a pianist practicing with a metronome).

\section{Flow and Stimulus}

Theories of stimulus indicate the basis of an activity that happens by practice in which the conclusions are more important than the ways and methods to do a certain task (Sansone \& Harackiewicz, 1996). Inclination of a person during an action should be disregarded. So far people who are involving in an activity constantly review their deed and test the significance and worth of their behaviors and decide whether to carry on the action or change it according to the assessments. The persons who are stimulated in an action and do it by their own choice, they will enjoy doing that and simply do it without any exhaustion. In fact they like to perform an action not because of getting a reward but because of being interested in that action (Hektner \& Csikszentmihalyi, 1996). When a person is deeply immersed in an activity, the inclination of being satisfied and motivated and enjoyed is regarded as prevailing power.

This kind of motivation is similar to the feeling we have whenever we decide to start playing our favorite games. These kinds of actions never go on unless they are agreeable or individuals are stimulated by outer prizes (Reser $\&$ Scherl, 1988).

As a whole, flow indicates the possibility that perhaps a person at first bored of doing an action such as playing with a friend or studying or even working with the computer. But, when they understand the occasion and they become more and more interested in the task doing it will change to be more attractive and pleasant. So that task will become an encouraging task as well. There will be a kind of improvement regarding ones objectives and aims in addition to progress of skills to do the certain task (Csikszentmihalyi \& Nakamura, 2001).

\section{Expository and Argumentative Genre}

Notifying, clarifying and identifying the writer's topic to the readers are the main objectives of Expository genre. Such writing is enormously used by students in different levels. The best expository text pays much attention to chronological incidents and its subject and theme. Giving directions and instructions to the reader or listener includes expository genre. The words signaling sequential events and ordering stages are important in this regard. Because its language is used as teaching or tutoring so second person pronoun is more dominant. In this genre, authors may extremely exaggerate about the topic. An important factor should be kept in minds that the writer should writes about the things done not every kind of discussions or deliberate talking. In fact it is informing and explaining genre. Accordingly, giving a direction or instruction needs an exact organization with improved mechanisms to describe all details in their own right places.

Argumentative genre presents a essential claim (or claims, depending on length and purpose) and supports the claim(s) using an argument derived from evidence and warrants. This type of genre is where you prove that your attitude, theory or hypothesis about an issue is exact or more truthful than those of others. In short, it is very analogous to the persuasive essay, but the dissimilarity is that you are arguing for your opinion as opposed to others, rather than straight trying to persuade someone to adopt your point of view. 


\section{Methodology}

\section{Participants}

Thirty three MA students studying in the University of Borujerd, Iran took part in the present research. All of the participants majored in English. In order to be sure that all of them have enough competence to take the TOEFL texts, only the second year university students were recruited. Their average age was 26 and the group included 20 females and 13 males. Of the participants, 15 had passed TOEFL exam before entering the university. All of the subjects expressed a positive attitude to experience testing different genres of TOEFL texts and they were so excited to know the results of the study.

\section{Instruments}

The instrument should set the ground for further studies in the realm of finding flow in reading different genres. For gathering data in the present research, two TOEFL texts were used. These instruments were used for 33 participants who were MA English students. The participants were asked to read the texts and fill out the Flow perception Questionnaire. According to Conti (2001) numerical sources of data were used to provide sufficient evidence to capture flow experiences. Consequently, the significant difference among two mentioned discourse genres in terms of magnitude of inducing flow in TOEFL text readers was calculated and this was done by using paired samples t-test for the significance of the difference among flow scores. In this way sig=.000 which is less than .05 . Therefore it can be concluded that there is statistically significant difference among two obtained means of discourse genres that shows a significant change in flow scores across two texts. As the table indicates, the calculated effect size is -0.23 which shows a large effect. That is, the difference between the means is large and meaningful and also it is worthy for the present research.

Tasks and Texts

In order to start the present study, two discourse genres from a TOEFL exam were selected: expository and argumentative (see Appendix A for the passages). These two texts were chosen based on the same length of words (around 200 words each text). Choosing the related texts from TOEFL passages made us sure about their reliability. In argumentative text, there are both giving information and presenting an argument with the supporting ideas and opposite ideas of a contrary issue. We should clearly take our stand and write as if we are trying to convince an opposing audience to adopt new beliefs or actions. The most important purpose is to persuade people to modify beliefs that many of them do not want to change.

Flow Perceptions Questionnaire

To measure flow, the Flow Perceptions Questionnaire adopted directly from Egbert (2003) was used. The Perceptions Questionnaire (see Appendix B) consisted of 14 items in the Likert format, having a 5-point scale from 5 (strongly disagree) to 1 (strongly agree). According to Mirlohi, Egbert, Ghonsooly (2011) for the purpose of item intelligibility, the questionnaire was pilot-tested before given to a group of 12 university juniors and the results showed that it was intelligible.

The received data from participants were entered into a SPSS 17 database. In fact each participant filled out the questionnaire two times for both texts. So, for the first time all of the expository passages were collected. After calculating each form score, the average of all questionnaires was measured. Then, the same process was repeated for argumentative genre too. The average of all the participants flow scores across the task made it possible to conduct analyses involving descriptive and inferential statistics.

Interview

After calculating the mean of flow scores of all subjects for both texts, it seemed to be necessary to interview those participants with highest and lowest scores in each text to know more about the participants' optimal experience measured through the Flow Perceptions Questionnaire. So, four students were selected accordingly: two with highest and lowest scores for the argumentative genre, and two with highest and lowest scores for the expository text. Gender of informants was not important here.

\section{Procedure}

Data collection was performed during students' regular class hours. In the first section of this study, students received expository text and its related Flow Perceptions Questionnaire. The second section was two weeks later with the same process, time and conditions for argumentative genre. It was strongly emphasized that the questionnaires had to be filled immediately after reading each text. The participants were made sure that they had enough time to fill out the questionnaire. So there was no limitation of time so that students have more control over reading the passages. Then, with two weeks interval four students were chosen for open interview. Before conducting the interview, the students were asked to review the texts not to forget any point in their assessments.

\section{Descriptive Statistics}

Table 1 summarizes the statistic of flow scores during all tasks as a result of paired Samples T-Test. As can be seen, there is a difference between the means of the argumentative text (46.09) and the expository text (71.96). 
TABLE 1

STATISTICS OF FLOW SCORES ACROSS EACH TASK.

Paired Samples Statistics

\begin{tabular}{|ll|l|l|l|l|l|l|}
\hline & N & Mean & Std. Deviation & Std. Error Mean & Minimum & Maximum & Range \\
\hline Pair 1 & Argumentative & 32 & 46.09 & 11.57962 & 2.04 & 26 & 76 \\
& Expository & 32 & 71.96 & 13.02970 & 2.30 & 54 & 80.0 \\
& Valid N(listwise) & 32 & & & & & 34.0 \\
\hline
\end{tabular}

It is important to say that according to Egbert (2003), the participants who scored 70 or above on any survey are designated as having experienced flow. In this way, the text in which the average score of all participants are 70 or above creates more flow. This score for the expository text is 71.96 . So it can be easily understood that this kind of text created flow in participants.

By comparing the results of Table 1, this fact can be easily found that the expository genre created more flow among applicants because only one applicant scored 76 for the argumentative text and sixteen participants with 70 score or above for the expository text. Although both texts were quite understandable and kind of easy, some texts aroused participants' curiosity, interest and attention because of the text content or topic so that it was probably boring for one and interesting for the other. Also, vocabulary and unfamiliar structure could be the other reason for this difference among the two texts. In fact, text topic, participants level of interest in the text, text characteristics, language issues such as structural difficulty, content germane to lifelike situations, individual appreciation of the text are important issues that have determinative affects on readers.

TABLE 2.

RESULTS OF PAIRED SAMPLES OF BOTH GENRES.

t-test

\begin{tabular}{|c|c|c|c|c|c|c|c|c|c|}
\hline & \multicolumn{5}{|c|}{ differences of both genres } & \multirow[b]{3}{*}{$\mathrm{t}$} & \multirow[b]{3}{*}{$\mathrm{df}$} & \multirow[b]{3}{*}{ Sig. (2-tailed) } & \multirow[t]{3}{*}{ Effect Size } \\
\hline & \multirow[b]{2}{*}{ mean } & \multirow[b]{2}{*}{ Std. Deviation } & \multirow[b]{2}{*}{ Std. error mean } & \multicolumn{2}{|c|}{$\begin{array}{l}95 \% \text { confidence interval } \\
\text { e difference }\end{array}$} & & & & \\
\hline & & & & lower & upper & & & & \\
\hline $\begin{array}{l}\text { Argumentative- } \\
\text { Expository }\end{array}$ & -25.87 & 19.06 & 3.36 & -32.74 & -19.00 & -7.67 & 31 & .00 & -0.23 \\
\hline
\end{tabular}

*The mean difference is significant at the .05 level.

According to Table 2, there is a significant difference between the results obtained from both argumentative and expository texts $(\mathrm{sig}=.000)$.

\section{RESULTS AND ANALYSIS}

There is a significant differences among discourse genres regarding flow in reading different discourse genres (sig=.000). By calculating mean of scores for each questionnaire in the first phase, and then measuring mean score of all questionnaires for each genre, significant effect of texts with different genres was indicated (effect size $=-0.23$ ) Statistics shows that the average flow score for the expository genre is 71.96. On the other hand, the average flow score for the argumentative discourse genre is 46.09 . This result showed that the expository discourse genre created more flow in participants and they were more likely to read this kind of text more than the other one.

The results of the study support and affirm the findings from the numerical phase. Necessarily, it was important for the researchers that the selected texts are quite similar in all respects and they are only different in terms of their genre. In the last phase of this research, four participants were interviewed: two participants with the highest flow score for each genre and the other two with the lowest flow score for each genre. Participants with the highest flow sore declared that the related text was so interesting for them that they wish to read it again and again and also narrate it for others. They added that they never felt to be bored of reading the text. In contrast, the results of interview with those with the lowest flow score showed that the text was so boring that they left the text and never liked to continue and repeat to read it again.

The conditions under which the participants in the present study just like the previous one experienced flow with the expository text and subsequently engaged in reading fit the flow model: 1) they were very interested in the subject of the text; 2) they established some kind of relationship between the text content and their world knowledge and experience;3) no task features prevented them from focusing intensely; and 4) the task could emotionally arouse the participants and optimally engage them. However, whenever a text can emotionally arouse readers and optimally involve them (like the expository text in this study); it is more likely to produce flow. This is clearly seen in the present study as nearly two thirds of the participants reported that they experienced flow while reading the expository text. 
The ability to enjoy challenges and then master them is a fundamental skill that is essential to individual development. Some people may not understand flow because of some obstacles. These obstructions may have roots in genetic failure to create inability to start pleasant relationship and connection. At that time there isn't any independence. These obstacles reduce learning and performing successful tasks. In such a way flow will be so difficult to be got. On the other hand, throughout flow, we are fully and deliberately engaged in performance so that we may not understand the world around us.

This study faced some difficulties and limitations as measuring flow, sample size and even motivated participants who were willing to spend their time for reading the texts that may be uninteresting and boring for them. The first conclusion obtained from this study regarded that the expository discourse genre created more flow in students in comparison with the argumentative genre. The second conclusion declared that participants with the highest flow score believed that the related text was more attractive, motivating and exciting as if they were very interested in the subject of the text, the texts were neither overmatched nor underused, they found some kinds of relationship between the text content and their knowledge and experience, the texts didn't prevent them from focusing intensely, and the text optimally engaged them. All of these features were more likely to produce flow. But students with the lowest flow score reported that they never experienced these issues during reading the text. They declared that the text didn't make them motivated and it wasn't challenging as if they couldn't have any control over the text.

The results of the present study are in accordance with previous research by Mirlohi, Egbert and Ghonsooly (2011) who studied the optimal experience for translation trainees. In their research the results indicated that flow existed in the classroom and that there were significant differences in the flow scores engendered by different genres just as the present research. The conclusions of both studies regard the adequacy of the Flow Perception Questionnaire that is a reliable instrument to gauge flow which may be indicative of the participants' true experiential states.

These findings are in a line with previous study regarding flow. The present research indicated examinees that distinguish feeling of inefficiency; they will experience distress or boredom, relating to the worth of well doing a job.

Initially, this study focused on expository and argumentative genres to see if they create flow in examinees or not. The same process can be performed for a wider range of genres. Second, this research has been done among TOEFL examinees. This issue can be expanded to other national and international exams. For example, placement test of university entrance for national and language proficiency tests like: IELTS, TOLEMO, GMAT, GRE for international ones. Third, gender is not noticed in the present study. So a study can be instructed to compare the reaction of each gender toward certain genres. Forth, the age of participants can also be an important variable to choose a special genre as more attractive and interesting one to create flow. Fifth, as other variables that can affect this issue are religious and cultural beliefs. A text with particular characteristics may be more fascinating and exciting for special culture than the other one or even some people with their own religious beliefs may accept texts contain their faiths and principles.

In the final step, the value and excellence of daily life must be noticed to be improved in any subjective or objective level. Maybe changing an action in to a useful and pleasant task is a hard job, but for those who wish to perform skillful and mastered job can be regarded as continual opportunities.

\section{APPENDIX A}

\section{Argumentative Genre:}

Your eyes are about three inches apart. It is the reason why you see the world in three dimensions. The separation gives your eyes two slightly different views of every scene you encounter. In the brains' visual cortex, these views are compared, and the overlap is translated into a stereoptic picture. To estimate relative instances, your brain takes a reading of the tension in your eyes muscles.

But you only see in 3-D up to about 200 feet. Beyond that, you might as well be one-eyed, your eyes are not far enough apart to give two very different views over long distances. Instead, you rely on experience to judge where things are; the brain looks for clues and makes its best guess. For example, it knows that near objects overlap far ones; that bright objects are closer than dim ones; and that large objects are nearer than small ones.

These "monocular cues" are what painters use into thinking a flat canvas is three-dimensional and miles deep. That's why paintings are much more convincing if you close one eye: Your brain hunts down all the clues the painter has dropped. But when both of your eyes are open, the brain gets more information and mixed signals. The paint may say miles, but the muscles in your eyes say inches.

\section{Expository Genre:}

After two decades of growing student enrollment and economic prosperity, business schools in the Unites States have started to face harder times. Only Harvard's MBA School has shown a substantial increase in enrollment in recent years. Both Princeton and Stanford have seen decreases in their enrollment. Since 1990, the number of people receiving Masters in Business Administration (MBA) degrees has dropped about 3 percent to 75000, and the trend of lower enrollment rates is expected to continue.

There are two factors causing this decrease in students seeking an MBA degree. The first one is that many graduates of four-year colleges are finding that an MBA degree does not guarantee a plush job on Wall Street, or in other financial districts of major American cities. Many of the entry-level management jobs are going to students graduating with Master of Arts degrees in English and humanities as well as those holding MBA degrees. Students have asked the 
question "Is an MBA degree really what I need to be best prepared for getting a good job?" The second major factor has been the cutting of American payrolls and the lower number of entry-level jobs being offered. Business needs are changing, and MBA schools are struggling to meet the new demands.

\section{APPENDIX B}

\begin{tabular}{|c|c|c|c|c|c|c|}
\hline \multicolumn{2}{|c|}{ Flow Perception Questionnaire: } & \multirow{2}{*}{$\begin{array}{l}\text { strongly } \\
\text { agree }\end{array}$} & \multirow{2}{*}{$\begin{array}{l}\text { somewhat } \\
\text { agree }\end{array}$} & \multirow{2}{*}{$\begin{array}{l}\text { neutral/no } \\
\text { opinion }\end{array}$} & \multirow{2}{*}{$\begin{array}{l}\text { somewhat } \\
\text { disagree }\end{array}$} & \multirow{2}{*}{$\begin{array}{l}\text { strongly } \\
\text { disagre }\end{array}$} \\
\hline 1 & This task excited my curiosity. & & & & & \\
\hline 2 & This task was interesting in itself. & & & & & \\
\hline 3 & $\begin{array}{l}\text { I felt that I had no control over what was } \\
\text { happening during this task. }\end{array}$ & & & & & \\
\hline 4 & $\begin{array}{l}\text { When doing this task I was aware of } \\
\text { distractions. }\end{array}$ & & & & & \\
\hline 5 & This task made me curious. & & & & & \\
\hline 6 & This task was fun for me. & & & & & \\
\hline 7 & I would do this task again. & & & & & \\
\hline 8 & $\begin{array}{l}\text { This task allowed me to control what I was } \\
\text { doing. }\end{array}$ & & & & & \\
\hline 9 & $\begin{array}{l}\text { When doing this task, I was totally absorbed } \\
\text { in what I was doing. }\end{array}$ & & & & & \\
\hline 10 & This task bored me. & & & & & \\
\hline 11 & $\begin{array}{l}\text { During this task, I could make decisions } \\
\text { about what to study, how to study it, and/or } \\
\text { with whom to study. }\end{array}$ & & & & & \\
\hline 12 & $\begin{array}{l}\text { When doing this task I thought about other } \\
\text { things. }\end{array}$ & & & & & \\
\hline 13 & This task aroused my imagination. & & & & & \\
\hline 14 & $\begin{array}{l}\text { I would do this task even if it were not } \\
\text { required. }\end{array}$ & & & & & \\
\hline
\end{tabular}

\section{REFERENCES}

[1] Conti, R. (2001). Time flies: Investigating the connection between intrinsic motivation and the experience of time. Journal of Personality, 69(1), 1-26.

[2] Csikszentmihalyi, M. (1996). Creativity: Flow and the psychology of discovery and invention. New York: HarperCollins.

[3] Csikszentmihalyi, M. (2004). What we must accomplish in the coming decades. Zygon, vol. 39, no. 2. (pp 45-54).

[4] Csikszentmihalyi, M., Abuhamdeh, S., Nakamura, J., (2005). Flow. (Chapter 32: pp 598-608). VI Self Regulatory Processes.

[5] Hektner, J., \& Csikszentmihalyi, M., (1996). A longitudinal exploration of flow and intrinsic motivation in adolescents. University of Chicago.

[6] Jackson, S. A., Thomas, P. R., Marsh, H. W., \& Smethurst, C. J. (2002). Relationships between flow, self-concept, psychological skills, and performance. Journal of Applied Sport Psychology, 13(2), 129-153.

[7] Mirlohi, M., \& Egbert, J., \& Ghonsooly, B. (2011). Flow in translation: Exploring optimal experience for translation trainees. John Benjamins Publishing Company, 23(2), 251-271.

[8] Nakamura, J., \& Csikszentmihalyi, M. (2001). Catalytic creativity: The case of Linus Pauling. American Psychologist, 56(4), 337-341.

[9] Reset, J. P., \& Scherl, L. M. (1988). Clear and unambiguous feedback: A transactional and motivational analysis of environmental challenge and self-encounter. Journal of Environmental Psychology, 8(4), 269- 286.

[10] Sansone, C., \& Harackiewicz, J. M. (1996). "I don't feel like it": The function of interest in self-regulation. In L. L. Martin \& A. Tesser (Eds.), Striving and feeling: Interactions among goals, affect, and selfregulation (pp. 203-228). Mahwah, NJ: Erlbaum.

Zeinab Azizi was born in 1982 in Borujerd, Lorestan Province, IR Iran. She finished her BA in English language and Literature in Islamic Azad University, Borujerd, Iran and obtained her Masters in Teaching English as a Foreign Language (TEFL) from the University of Tehran, Iran in 2009. She is currently teaching at the university level in Borujerd. And she is a PhD student of Ferdowsi University of Mashhad. She also compiled a course-book on reading comprehension in English published for university students. Miss Azizi is a keen researcher in the areas of language teaching and learning. Her main research interests are teaching English grammar within the framework of Zone of Proximal Development and corrective feedback among university language learners. She is a member of the Teachers of English Language and Literature Society in Iran (TELLSI).

Behzad Ghonsooly is professor of Applied Linguistics. He has published more than 50 articles in national and international journals. His main research interests are 'language testing', 'introspection in reading' and 'psycholinguistics'. 